\title{
ANALYSIS OF TYPICAL STRUCTURES OF DYNAMIC SYSTEMS OF MACHINING OF ELASTIC-DEFORMABLE SHAFTS WITH LOW RIGIDITY
}

\author{
Antoni Świć1, Arkadiusz Gola', Dariusz Wołos' \\ 1 Institute of Technological Systems of Information, Lublin University of Technology, Nadbystrzycka Street 36, \\ 20-618 Lublin, Poland, e-mail: a.swic@pollub.pl; a.gola@pollub.pl; d.wolos@pollub.pl
}

Received: 2017.06.29

Accepted: 2018.03.18

Published: 2018.09.01

\begin{abstract}
In the process of machining of shafts with low rigidity it is difficult to achieve the required parameters of accuracy of form and dimensions and of surface quality. Under specific conditions, low inherent rigidity and the relatively low shaft rigidity, compared to the rigid assemblies of the machine tool, cause vibrations. The paper presents a 7-level hierarchical mathematical model of the system of longitudinal turning and a mathematical model of the dynamic system of machining of shafts with low rigidity in the elastic-deformable state, taking factors interfering with and destabilising the process of shaft machining into account. For the purpose of validation of the models, a study was conducted on the conformance of the dynamic characteristics of the mathematical model with the actual object. The study was realized on specially designed experimental workstation for the study of characteristics of the dynamic system of turning of elastic-deformable shafts with low rigidity. The experiment demonstrated a high conformance of the dynamic characteristics of the mathematical model with the actual object.
\end{abstract}

Keywords: low rigidity, manufacturing systems, experimental study, machining.

\section{INTRODUCTION}

Elastic-deformable shafts with low rigidity are more and more frequently used in various mechanisms and machines. Because of their application in aerospace industry, military, energy and shipbuilding industry, face high requirements with regard to their surface quality parameters owing to the significance of these parameters for the operational reliability of such parts $[3,8$, 13]. Their machining is more complex than that of rigid shafts $[6,14]$. In order to comply with the requirements, new solutions must therefore be implemented, already at the stage of designing technologies for producing these parts, e.g. through proper modelling, prediction or simulation techniques $[10,15,26]$.

The problem of machining low-rigidity shafts was widely discussed in the literature. There are many publications concerning the problem of stability lobes $[2 \div 23]$, definition of cutting conditions $[4,18]$, machining forces and error prediction $[16,17]$, surface quality modelling $[1,7$, 11, 19] or chatter suppression [15]. Moreover, the problem of simulation of low-rigidity part machining was in the special interests of researchers $[5,9,15]$. However, it is quite difficult to find papers concerning the problem of modelling of the dynamic system of turning shafts with low rigidity in the elastic-deformable state.

The technological system of machining of shafts with low rigidity is a systemic system [25]. The systemic category includes objects and processes composed of separate parts, elements and objects, characterised by the possibility of comprehensive (complete) functioning. Any technological system can be characterised by means of a specific set of features [26]: 
- relations with the environment (in the case under consideration - with interference and the initial error of the semi-finished product);

- realized functions, allowing the assurance of specific parameters of machining accuracy in the technological process;

- structure;

- functional properties, determined by the character of transmittance.

The specified set of characteristics fully corresponds to the technological systems of machining of elastic-deformable shafts with low rigidity and their mathematical models, taking into account the properties of the system of control under steady and dynamic conditions.

The conventional methods of achieving accuracy of machining low-rigidity shafts, based on multi-pass machining, reduced machining parameters, steadies, and hand lapping, cause a significant lowering of efficiency, are uneconomical and inefficient, and preclude the automation of the process of machining [20,21,24]. This causes the necessity of developing new theoretical (e.g. suitable models of the run of such processes, models of the dynamics of the layout and the process of turning) and practical (methods of shaft machining eliminating the shortcomings of conventional machining methods) solutions. This paper presents mathematical model of the dynamic structure of machining of shafts with low rigidity in the elastic-deformable state of the system which is referred to the problem of the dynamics of the layout and the process of turning.

\section{MATHEMATICAL MODELS OF TYPICAL STRUCTURES OF SYSTEMS OF MACHINING OF SHAFTS WITH LOW RIGIDITY}

As systemic objects, mathematical models of dynamic systems of machining of elastic-deformable parts take into account important, and at the same time, various specific features of functioning of the object of control.

The paper presents a 7-level hierarchical mathematical model of the system of longitudinal turning and a mathematical model of the dynamic system of machining of shafts with low rigidity in the elastic-deformable state, taking into account factors interfering with and destabilising the process of shaft machining.

The generalised mathematical model of the system of longitudinal turning and the mathemat- ical model of the dynamic system are situated at level I - the highest hierarchical level (Fig. 1).

The generalised mathematical model $G_{T}(s)$ situated at hierarchical level II corresponds to the system of equations and the structural schematic presented in [18].

At hierarchical level III of the mathematical model of the dynamic system of longitudinal turning of elastic-deformable shafts with low rigidity there takes place a division into two models, in the case of the first of which $K_{k r} \neq 0$ (coefficient of effect of tool clearance angle on elastic deformation of shaft), $\kappa_{r} \neq 90^{\circ}$ (tool clearance angle); and of the second $K_{k r}=0, \kappa_{r}=90^{\circ}$. The operator transmittances $G_{T}(S), G_{T 3}(S)$ and the gain coefficients $A_{l}, A_{1}$ ' and $B_{l}, B_{l}$, taking into account $K_{k r}$ [15]. At that level there are also the mathematical models of the dynamic system of the processes of oscillation grinding $G_{s c}(s)$ and of external plunge grinding $G_{s c}$ ' $(s)$ which can be considered as specific cases of the mathematic model of the dynamic system of turning. The corresponding relations describing plunge grinding, taking into account that in oscillation grinding $K_{k r}=0, K_{b z}=$ $0, m_{x} K_{x}=0, K_{x y}=0$.

At hierarchical level IV there are the mathematical models of the system of turning $G_{T}(s)$, $G_{T 1}$ ' $(s), G_{T 2}(s), G_{T 2}$ ' $(s), G_{T 3}(s)$, differing in the values of gain coefficients $A_{1} A_{2}, A_{1}$ ' and $A_{2}$ ' in the case of the dynamic system of oscillation grinding $-G_{s c}(s)$, and of external plunge grinding $-G_{s c}{ }^{\prime}(s)$.

Situated at hierarchical level V are the mathematical models of the dynamic system, obtained with the omission of the effect of the closed feedback loop being affected by coefficient $m_{x} K_{x}<<1$ and transmittance $\left(1-e^{-S t}\right)$, on the increment of the thickness of the machined layer.

At hierarchical level VI there are partial models of the dynamic system, omitting the effect of internal feedback $m_{x} K_{x}<<1$ and elastic deformations relative to coordinate $\mathrm{Z}$ on the change in the depth of machining $K_{b z} K_{z} n_{z}<<1$.

Situated at hierarchical level VII - the lowest one - are the partial mathematical models of the dynamic system of machining, taking into account only the effect of elastic deformations relative to coordinate $\mathrm{Y}$ on the increment of the thickness of machined layer $\left(K_{x y}<<1\right)$ in turning, external plunge grinding and oscillation grinding - two partial models [22].

Typical structures of dynamic systems of forming elastic-deformable shafts with low rigidity at various force-type regulatory effects, 


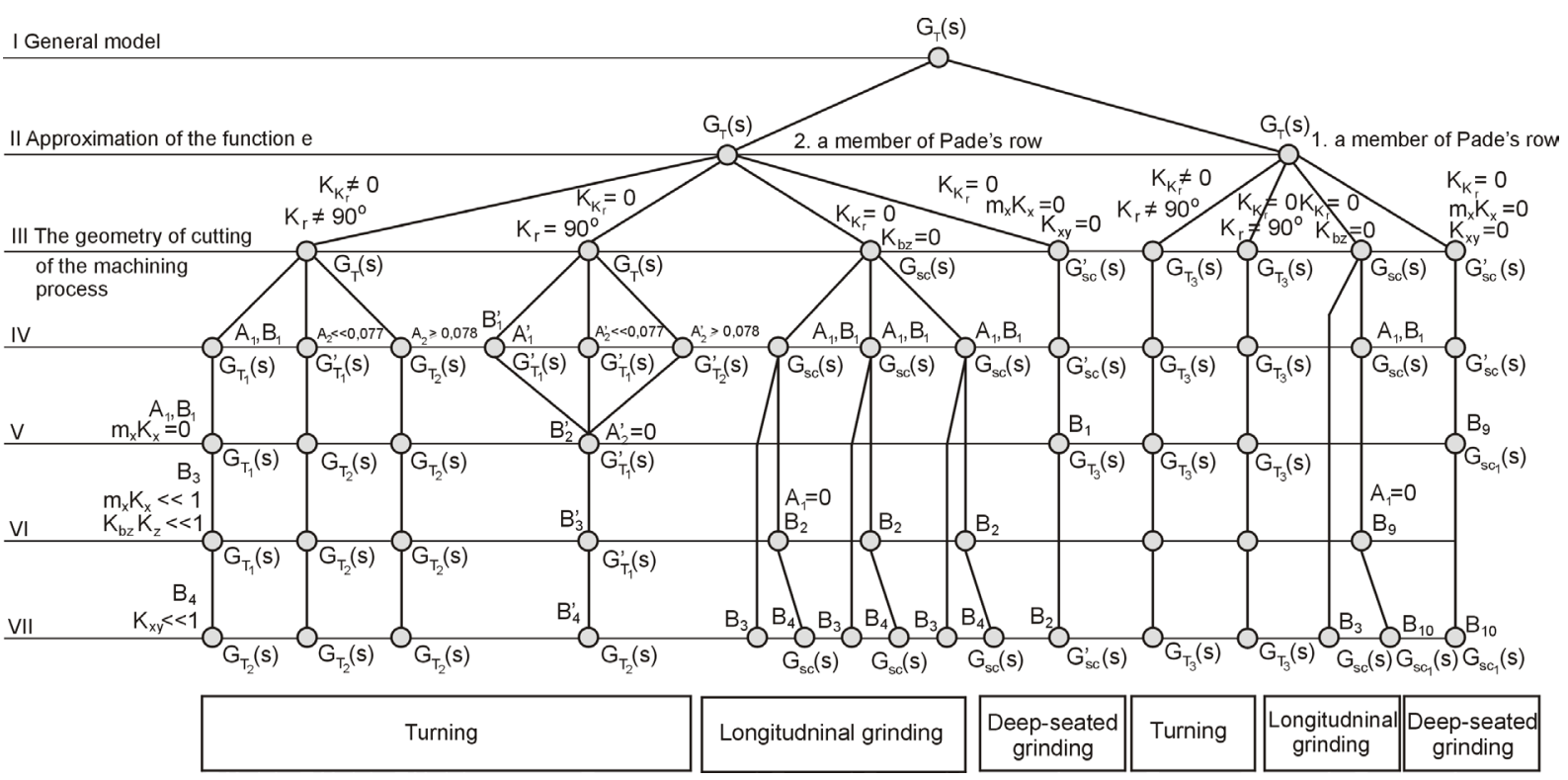

Fig. 1. Hierarchical levels MM of the dynamic system of machining of shafts with low rigidity in elastic-deformable state

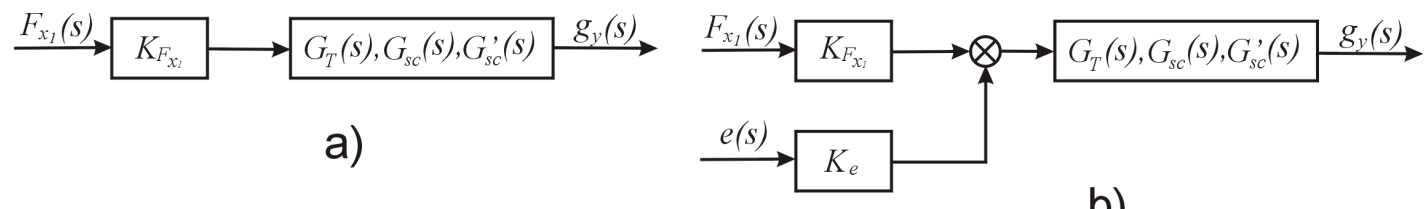

b)

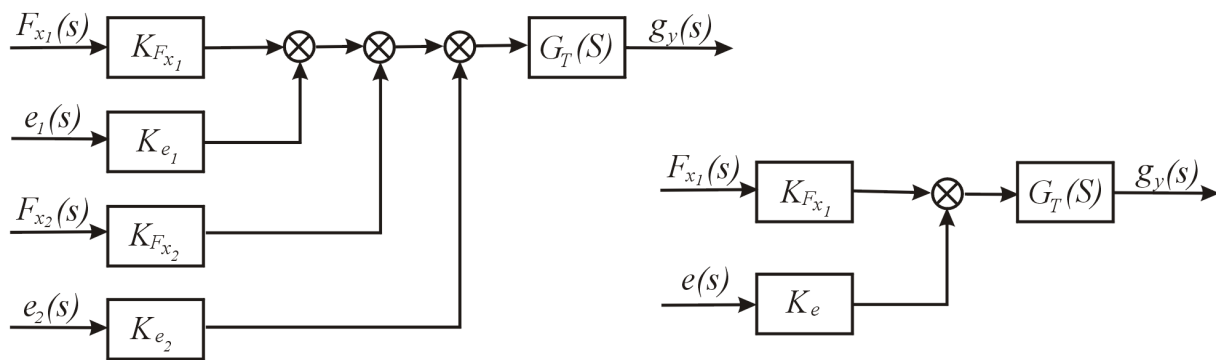

c)

d)

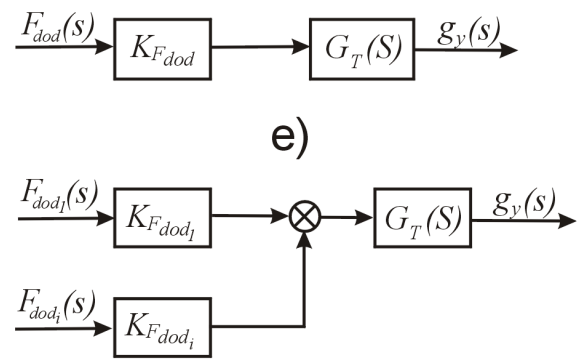

g)

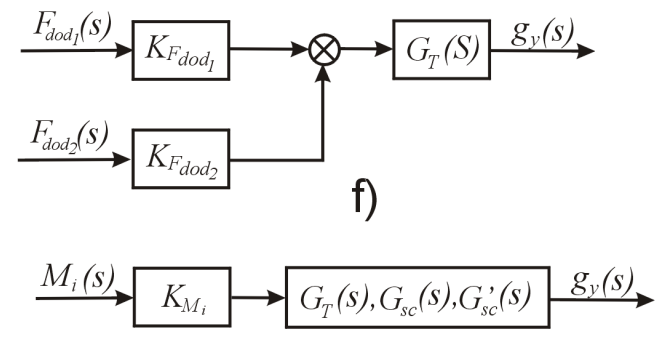

h)

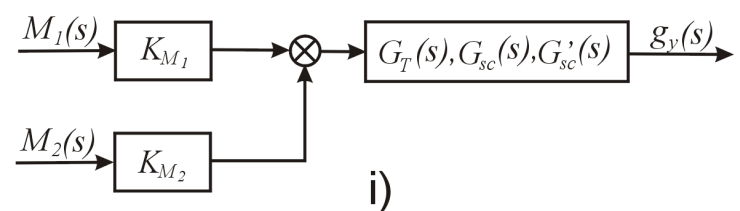

Fig. 2. Typical structures of dynamic system of machining shafts with low rigidity in elastic-deformable state 
for which typical transmittances of the object of control gains coefficients relative to those effects have been determined in accordance with the relationships given in [20,21], are presented in Fig. 2. In case of the dynamic system of longitudinal turning, taking into account suitable regulatory effects, one can use the structures developed for oscillation grinding - Fig. 2a, b, h, i, and of the dynamic system of longitudinal turning, taking into account suitable regulatory effects, those for oscillation grinding - Fig. $2 \mathrm{~g}$, i.

Therefore, mathematical models of dynamic systems - objects of control - can be classified according to the amount and quality of information adopted for the mathematical model. This allows the systematisation of design work and technological preparation of processes, as well as the development of automatic control systems and adaptive systems.

\section{COMPARATIVE ANALYSIS OF RESULTS OF THEORETICAL AND EXPERIMENTAL STUDIES OF CHARACTERISTICS OF THE DYNAMIC SYSTEM OF MACHINING OF ELASTIC-DEFORMABLE SHAFTS WITH LOW RIGIDITY}

\section{Metodology of experimental study and experimental workstation}

The presented analytical approach to the construction of the mathematical model of the dynamic system of the process of turning of elasticdeformable shafts with low rigidity is related with the introduction of numerous reducing or simplifying assumptions. Validation of their correctness requires experimental studies. The objective of such a study is the estimation of the degree of conformance of the dynamic characteristics of the mathematical model with those of the actual object. The study of the dynamic characteristics of the technological processes of machining should be conducted on the basis of experiments determining the responses of the object of control to typical stimuli evoked on purpose.

The simplest typical test stimulus is a stepwise change of the input signal. It is assumed that control is realized according to the channel of force-type effects or stimuli, in this case the axial tensile force generating the elastic-deformable state of the part. Machining is conducted at constant values of the force of machining, longitudinal travel, specific depth of machining and initial value of the tensile force. With a step-wise change of the regulatory effect - tensile force, transition processes were recorded - changes of the elastic deformations of the machined shaft at various cross-sections of the semi-finished product. Analogously, the process of transitional processes was recorded, relieving the load on the semi-finished product with the tensile force, from the maximum to the initial value, determined in each case by the geometric parameters of the part and by the machining parameters.

The conformance of the shape of the experimental curve relative to the curve obtained on the basis of the mathematical model can be estimated in accordance with the methodology presented in [11]. The transitional experimental characteristic is approximated by a curve corresponding to an aperiodic link. It is known that the transitional characteristic of such a link in time $T_{I E}$ attains the value of $0,63 g_{g_{u s t}}$, where $g_{\text {oust }}$ - value of the input coordinate - elastic deformation of the machined part. At specific conditions of machining in the dynamic system, the time constant $T_{1}$ was calculated in accordance with the relations presented in [19]. The error can be calculated from the relation:

$$
\delta=\left|\frac{T_{1 E}-T_{1}}{T_{1 E}}\right|
$$

A design of an experimental workstation was developed for the study of characteristics of the dynamic system of turning of elastic-deformable shafts with low rigidity. The station is designed for the study of static (Fig. 3a), dynamic (Fig. 3b) and frequency characteristics (Fig. 3c) in the machining of shafts with low rigidity. The design was developed taking into account the shortcomings and the advantages of existing experimental workstations. It was constructed on the base of machine tool type 1I6164P. It is composed of the following (Fig. 3a): low-rigidity shaft 1 fixed in self-centring three-jaw chuck 2 and sleeve grip 3, tailstock 4 with a tensioning mechanism in the form of pneumatic actuator 5. The actuator is connected to proportional control unit 6 (FESTO). Special bracket 9 mounts eddy current sensor 11 (Bentley Nevada, USA) recording the elastic deformations of shaft 1 . Bracket 9 is rigidly mounted on the ways of machine tool 14. In tool post 7 of carriage 8 , with the use of bracket 12, model compression dynamometer 13 is mounted, type DOSM-3-02 (measurement range from 196 to $1960 \mathrm{~N}$ ). Radial components $F_{p}$ of machining force were simulated by means of 
dynamometer 13. The value of axial tensile force was determined in control unit 6 . The workstation was used for the study of elastic deformations of shafts with diameters $d=2-15 \mathrm{~mm}$ and length of 100,200 and $300 \mathrm{~mm}$.

Recording of transitional characteristics of the dynamic system during the turning of shafts with low rigidity (Fig. 3) was conducted with the use of sensor 10 mounted on bracket 15 which was rigidly installed on carriage 8 . Shaft machining was conducted by means of a cutting tool installed in tool post 7. Information on the transitional characteristics, converted by measuring generator 16 and analogue-digital converter $(P A / C) 17$ is logged in digital form in the fixed memory store of computer 18 . This operation is realized analogously to oscillogram logging in an analogue oscilloscope, which allows obtaining oscillograms of any desired length.

The acquisition and estimation of frequency characteristics of the dynamic system is possi- ble through the use of special module (Fig. 3c). Characteristics of the system (static, transitional, frequency) are necessary for the diagnostics and control of the process of machining of shafts with low rigidity.

The block of vibration recording, with the use of the $P C$, operates according to the following schematic. Deformations and vibrations of the dynamic system are recorded by the eddy current sensor 10, signal from which is supplied to the measuring generator 19 where it undergoes modulation and amplification. Amplified signal from the output of measuring generator 19 is supplied via special separator 20 to the input of the analogue-digital converter $(P A / C) 17$ $P C$ and it is logged in digital form in the fixed memory of the computer. There can be more than three recording sensors. The experimental workstation includes the special separator 20 which connects the sensors to the input of $P A / C$ in a sequential manner.
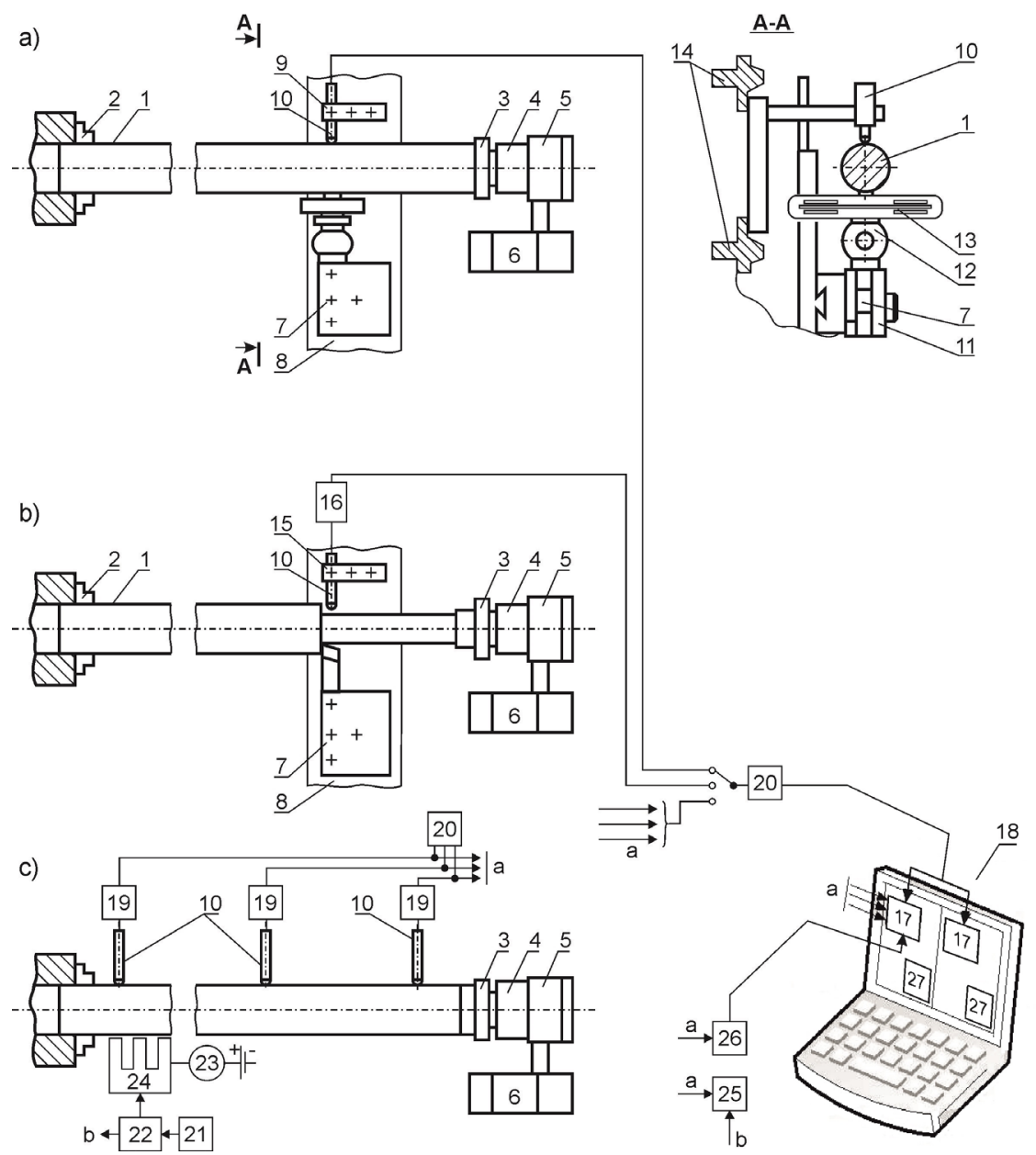

Fig. 3. General scheme of the experimental workstation for the study of characteristics of dynamic systems of turning of elastic-deformable parts with low rigidity 
Recording of amplitude-frequency characteristics of the dynamic system is conducted according to the following schematic. The frequency of input effect is determined in generator 21 from which the signal, via amplifier 22, is supplied to the control winding of vibrator 24 . The magnetising winding is supplied with direct current from the power supply. The magnetic-force effects of the vibrator are transferred onto the object, where the magnetic vibrations are converted into mechanical vibrations. The current flowing through the winding of the electromagnetic vibrator, and its traction force at a change of frequency of the input effect are controlled by means of ammeter 23. Vibrations of the part, recorded by eddy current sensors 10 and amplified by amplifiers 19 , are recorded by means of phase-sensitive voltmeter 25, to the input of which signal is supplied from power amplifier 22. The signals obtained are compared in the phase-sensitive voltmeter. The actual and the imaginary parts of the amplitude-frequency characteristics are determined. For recording the shift of the axis of the semifinished product a low-pass filter 26 is installed in the workstation. Signal from sensor 10, passed through the low-pass filter 26, retains a constant component proportional to the shift of the axis of the machined part. The signal obtained is presented on the computer screen or logged in its memory 18 .

The amplitude-frequency characteristics are recorded with the use of the program analyser of spectra 2 and oscillograms saved in computer memory 18.

Recording eddy currents is performed with the use of a sensor, characterised by the following parameters: method of measurement - contactless; small dimensions - diameter $6 \mathrm{~mm}$, length $30 \mathrm{~mm}$; linear characteristics at slot from 2 to $2,5 \mathrm{~mm}$; sensitivity $10 \mathrm{mV} / 1 \mu \mathrm{m}$. The small size and cylindrical shape of the sensor body with external thread allow its installation in hard to access places, and also to bring it close to the machining zone. The sensor registers changes of electromagnetic field in relation to the distance between the winding generating eddy currents and the surface of the part under study. The technique of vibration recording by means of eddy currents has a significant advantage - it is practically inertia-free as the rate of information flow from the converter is equal to the speed of propagation of electromagnetic field. The boundaries of measurement of vibrations frequency are from zero to hundreds of $\mathrm{kHz}$. The range of amplitude measurement - from a micrometre to millimetres. The sensor has a measurement generator from the output of which constant voltage is taken off. A two-channel computer audio card is used as the $\mathrm{PA} / \mathrm{C}$. The logging and analysis of oscillograms is done with the use of a special program - analyser of frequency spectra.

\section{Results of experimental study of characteristics of dynamic system of turning of elastic-deformable shafts with low rigidity}

In the study of the responses of an object to test effects it is necessary to determine the inherent inertia of the drive element of the system the pneumatic drive. Analysis of the equation of movement of the pneumatic element shows that its dynamic properties can be approximately described by means of an operator transmittance of the aperiodic element as:

$$
G_{p}(s)=\frac{K_{p}}{T_{p} \cdot s+1}
$$

where the equivalent time constant $T_{n p}$ - depending on the initial position of the piston of the pneumatic actuator equals $0,01-0,02 \mathrm{~s}$.

The increase of elastic deformations relative to coordinate $Y$ was analysed in relation to the initial coordinate of the object when supplying a unit step-wise signal on its input, taking into account the inertia of the actuator. The operator transmittance of the object is equal to:

$$
\Delta g_{y}(s)=\frac{1}{s} G_{p r}(s) G_{F_{g y}}(s)=\frac{K_{p r} K_{0 F_{g y}}\left(T_{05} s+1\right)\left(T_{06} s+1\right)}{s\left(T_{p r} s+1\right)\left(T_{01} s+1\right)\left(T_{02} s+1\right)}
$$

Based on earlier research $[19,20]$ it was concluded that the time constants in the numerator and the denominator of the operator transmittance of the object have similar values, and thus its dynamic properties are similar to the properties of the proportional element, i.e. the transitional process at step-wise signal supplied to the input of the actuator is most frequently determined by the properties of that element (Fig 4). For example, the experimental study of the time characteristics involved the machining of a shaft of steel $\mathrm{C} 45$, with diameter of $5 \mathrm{~mm}$ and length of $200 \mathrm{~mm}$. Machining parameters: $a_{p}=0,2$ 


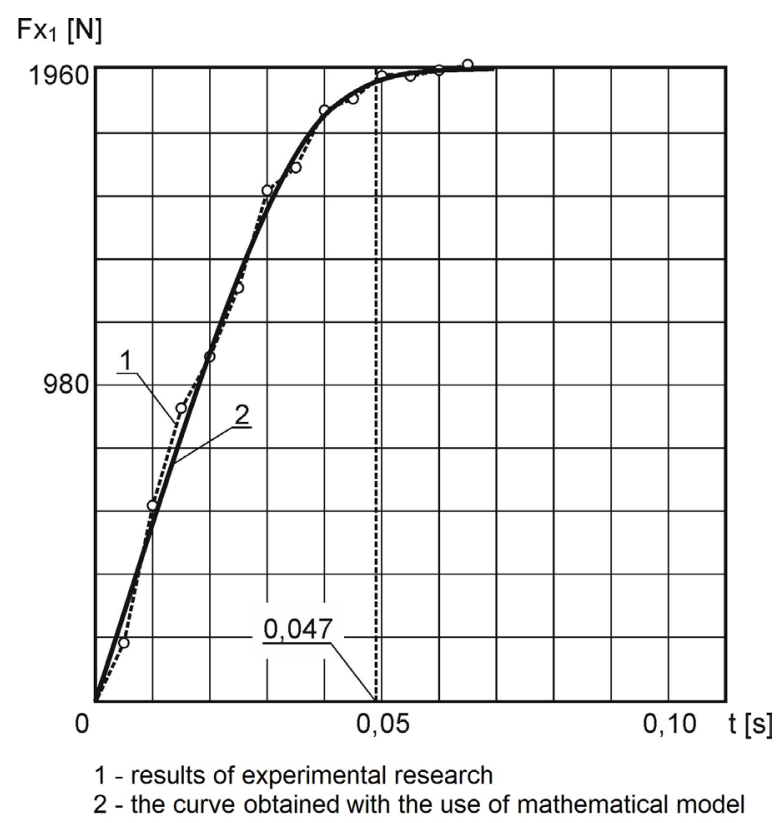

Fig. 4. Experimental verification of the time constraints of the operator transmittance

$\mathrm{mm}, f_{1}=0,2 \mathrm{~mm} / \mathrm{r}, \kappa_{r}=90^{\circ}, v_{c}=0,33 \mathrm{~m} / \mathrm{s}$, value of initial tensile force $F_{x l}=1980 \mathrm{~N}$.

The values of $m_{x}=m_{v}=0,61 \cdot 10^{6} \mathrm{~N} / \mathrm{m}$ were determined with the use of guide-books. In the case under consideration, the elasticity coefficients of the elastic system relative to coordinate $X$ are determined primarily by the elastic properties of the machine tool $-h_{x x}=3 \cdot 10^{-7} \mathrm{~m} / \mathrm{N}$, and relative to coordinate $Y$ - by the elastic properties of the part. The calculations were performed following the 4 relations given in [20], in the case when the machining force, applied at the centre point of the part, determines the initial value of elastic deformations of the part $g_{y 0}=0,11 \cdot 10^{-3} \mathrm{~m}, h_{y y}=1,2 \cdot 10^{-}$ ${ }^{6} \mathrm{~m} / \mathrm{N}$. The values of coefficients $B_{0}$ and $B$ are equal to $B_{0}=0,18, B=0,17$.

Taking into account that the values of coefficients $B$ and $B_{0}$ are similar, the object can be assumed to be a proportional element, and the transitional characteristic is determined by the inertia of the actuator. As follows from the experiment carried out, in these conditions the curve of the transitional process is exponential, and the time constant equals $T_{p r}$. When applicate the initial tensile force to the end of the elastic-deformable more than three times increase of the accuracy of the machining process can be obtained (Fig. 5).

Loading a semi-finished product with a tensile force, causing the elastic-deformable state, is equivalent to the creation of an additional support causing an increase of the static stiffness of the part. Therefore, it can be assumed that the alignment and the fixing of semi-finished products can be realized in self-centering grips or in a spring sleeve.

\section{CONCLUSION}

Mathematical models of dynamic systems objects of control - can be classified with relation to the amount and quality of information adopted in the mathematical model. This allows the system-

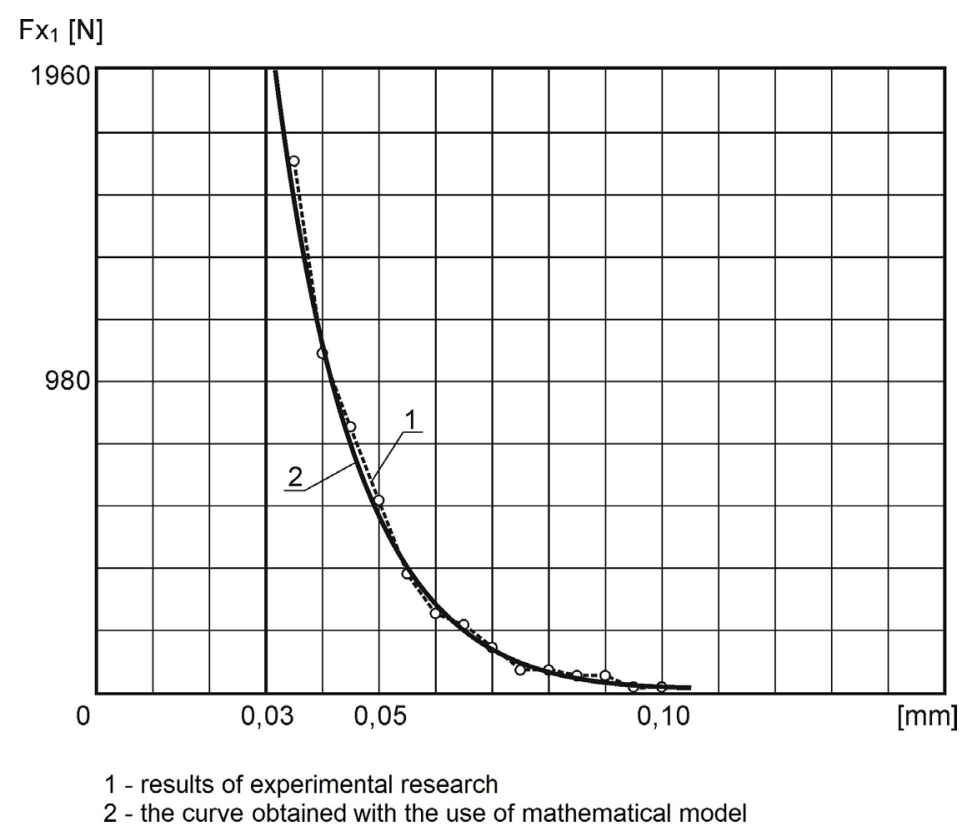

Fig. 5. Elastic deformations of the shaft according to the value of the initial tensile force 
atisation of design work and technological preparation of processes, as well as the development of automatic control systems and adaptive systems.

Validation of the analytical models of the dynamic system of the process of turning of elasticdeformable shafts with low rigidity was conducted on a specially designed experimental workstation. The study of the dynamic characteristics of technological processes of machining was performed on the basis of experiments in the course of which the responses of the object of control to specially initiated typical effects were determined.

The particular results of provided experiments allow to draw following conclusions:

- time constants in the numerator and the denominator of the operator transmittance of the object have similar values,

- the transitional process at step-wise signal supplied to the input of the actuator is most frequently determined by the properties of that element,

- the elasticity coefficients of the elastic system relative to coordinate $X$ are determined primarily by the elastic properties of the machine tool $-h_{x x}=3 \cdot 10^{-7} \mathrm{~m} / \mathrm{N}$, and relative to coordinate $Y$ - by the elastic properties of the shaft.

Moreover, the study demonstrated that the time constants in the numerator and the denominator of the operator transmittance of the object have similar values, and thus its dynamic properties are similar to the properties of the proportional element, i.e. the transitional process at stepwise signal supplied to the input of the actuator is most frequently determined by the properties of that element. Therefore, the object can be assumed to be a proportional element, and the transitional characteristic is determined by the inertia of the actuator. The experiment shows that in these conditions the curve of the transitional process is exponential, and the time constant equals $T_{p r}$. The result is that the application of tensile force to the end of the elastic-deformable shaft allows to increase the accuracy of the machining process more than three times.

\section{REFERENCES}

1. Arnaud L., Gonzalo O. Seguy, S. Jauregi H., Peigne, G.: Simulation of low rigidity part machining applied to thin-walled structures. International Journal of Advanced Manufacturing Technology, Vol. 54, 2011, 479-488.

2. Bajić D., Celent L., Jozić S.: Modeling of the influence of cutting parameters on the surface roughness, tool wear and cutting force in face milling in off-line process control. Strojniski Vestnik - Journal of Mechanical Engineering, Vol. 58, 2012, 673-682.

3. Bing D., Guang-Bin Y., Yan-Qi G., Xue-Mei W., Yu-Xin L.: Machining surface quality analysis of aluminium alloy thin-walled parts in aerospace, International Journal of Security and its Applications, Vol. 9, No. 11, 2015, 201-208.

4. Campa F. J., de Lacalle L.N.L., Urbikain G., Ruiz D.: Definition of cutting conditions for thin-to-thin milling of aerospace low rigidity parts, Proceedings of the ASME International Manufacturing Science and Engineering Conference 2008, Vol. 1, 2008, 359-368.

5. Campomanes M.L., Altintas Y.: An improved time domain simulation for dynamic milling at small radial immersions. Trans ASME, Journal of Manufacturing Sciences and Engineering, Vol. 125, 2003, 416-422.

6. Dies E., Perez H., Marquez J., Vizan A.: Feasibility study of in-process compensation of deformations in flexible milling, International Journal of Machine Tools and Manufacture, 2015, Vol. 94, 1-14.

7. Huang Y.A., Liu H.M., Yin Z.P., Xiong, Y.L: Complex surface machining: thermo-mechanical analysis for error prediction of low-rigidity workpiece. Lecture Notes in Artificial Intelligence, Vol. 5928, 2009, 666-677.

8. Izamshah R., Mo J.P.T., Ding S.: Hybrid deflection on machining thin-walled monolithic aerospace components, Journal of Engineering Manufacture, Vol. 226, No. 4, 2012, 592-605.

9. Li H., Shin Y.C.: A comprehensive dynamic and milling simulation model. Trans ASME, Journal of Manufacturing Sciences and Engineering, Vol. 128, 2006, 86-95.

10. Li H., Shin Y.C.: Integration of thermo-dynamic spindle and machining simulation models for a digital machining system. The International Journal of Advanced Manufacturing Technology, Vol. 40 (7-8), 2009, 648-661.

11. Lopes L.G.D., Gomes J.H.D., de Paiva, A.P. Barca, L.F. Ferriera, J.R. Balestrassi P.P.: A multivariate surface roughness modelling and optimization under conditions of uncertainty. Measurement, Vol. 8, No. 46, 2013, 2555-2568.

12. Lorong P., Coffignal G., Cohen-Assouline S.: Simulation du comportement dynamique d'un systeme usinant: modelisation de l'interaction outil/matiere en presence d'une piece flexible. Mecanique and Industries, Vol. 9, 2008, 117-124.

13. Miao L. , Yu H., Cui W., Jiang H., Li Y., Wang R., Gao X.: Analysis and research of structure and process characteristic based on low rigidity shell part, 7th International Conference on Mechanical and Electronics Engineering, ICMEE 2015; Dalian; 
China; 26 September 2015 through 27 September 2015; Code 121403.

14. Mundim R.B., Borille A.V.: An approach for reducing undesired vibrations in milling of low rigidity structures, International Journal of Advanced Manufacturing Technology, Vol. 88, Issue. 1, 2017, 971-983.

15. Qi H., Tian Y., Zhang D.: Machining forces prediction for peripheral milling of low-rigidity component with curved geometry, International Journal of Advanced Manufacturing Technology, Vol. 64, No. 9, 2013, 1599-1610.

16. Ratchev S., Liu S., Huang W., Becker A.A.: Milling error prediction and compensation in machining of low-rigidity parts. Int J Mach Tools Manuf, Vol. 44, No. 15, 2004, 1629-1641.

17. Ryu, S. H., Lee H. S., Chu, C. N.: The form error prediction in side wall machining considering tool deflection. Int. J Mach Tools Manuf, Vol. 43, 2003, 731-737.

18. Świć A., Draczew A., Gola A: Method of achieving accuracy of thermo-mechanical treatment of low-rigidity shafts. Advances in Science and Technology. Research Journal, Vol. 10, No. 29, 2016, 62-70.

19. Świć A., Gola A., Wołos D., Opielak M.: Microgeometry surface modelling in the process of lowrigidity elastic-deformable shafts turning, Iranian Journal of Science and Technology - Transactions of Mechanical Engineering, Vol. 41, No. 2, 2017, pp. 159-167, doi:10.1007/s40997-016-0050-4.
20. Świć A., Gola A., Control of Accuracy of Forming Elastic-Deformable Shafts with Low-Rigidity, Advances in Intelligent Systems and Computing, Vol. 620, 2018, 107-114.

21. Świć A., Wołos D., Zubrzycki J., Opielak M., Gola A., Taranenko V.: Accuracy control in the machining of low rigidity shafts, Applied Mechanics and Materials, 613, 2014, 357-367.

22. Tian L.Z., Wu J.H., Xiong Z.H., Ding H.: Active chatter suppression in turning of low-rigidity workpiece by system matching. Lecture Notes in Artificial Intelligence, Vol. 9245, 2015, pp. 609-618.

23. Urbicain G., Olvera D., Fernández A., Rodríguez,A., Tabernero, I., López de Lacalle L.N.: Stability Lobes in Turning of Low Rigidity Components. Advanced Materials Research, Vol. 498, 2012, pp. 231-236.

24. Wang G., Li W.-L., Tong G., Pang C.-T., Improving the machining accuracy of thin-walled parts by online measuring and allowance compensation, International Journal of Advanced Manufacturing Technology - article in press.

25. Wang X., Wang A., Ly Y.: A Variable Stiffness Analysis Model for Large Complex Thin-Walled Guide Rail, MATEC Web Conf., Vol. 77, 10002, 2016.

26. Zhang X., Yong L., Feng X.: The study of the simulation of low rigidity, variable cross-section shaft electrolytic grinding, Advanced Materials Research, Vol. 668, 2013, 465-469. 